\title{
Construction of Interactive Teaching System for Course of Mechanical Drawing Based on Mobile Augmented Reality Technology
}

\author{
https://doi.org/10.3991/ijet.v13i02.7847 \\ Cheng Juan( $(\varpi)$ \\ Wuhan University, Wuhan, China \\ Jingdezhen University, Jingdezhen, Jiangxi, China \\ ilovesweet@gmail.com \\ Wang YuLin \\ International School of Software, Wuhan University, Wuhan, China \\ Tjondronegoro Dian W. \\ Southern Cross University, Gold Coast, Australia \\ Song Wei \\ Shanghai Ocean University, Shanghai, China
}

\begin{abstract}
The teaching aim of mechanical drawing is to cultivate the students' graphic interpreting ability, plotting ability, inter-space imagination and innovation ability. For engineering students in Chinese universities, a mechanical drawing course focused on 3D and 2D inter-space transformation is often difficult to master. The ordinary dull teaching method is insufficient to stimulate students' spatial imagination capability and interest in learning and cannot meet teachers' need to explain complicated graphical relationships. In this paper, we design an interactive teaching system that uses mobile augmented reality to improve the learning efficiency of a mechanical drawing course. To check the effect of the proposed system, we carried out a case study of two classes in mechanical drawing. The results demonstrate that the class for which an interactive teaching system based on mobile augmented reality technology was adopted is significantly superior to the class for which the ordinary dull teaching approach was adopted with regard to the degree of students' proficiency in the course's key, difficult content areas, their spatial imagination capability, and their interest in learning and study after class.
\end{abstract}

Keywords-Augmented Reality, Mechanical Drawing, Interactive teaching system, multimedia teaching application

\section{$1 \quad$ Introduction}

Mechanical drawing or mechanical engineering drawing is one of the fundamental courses for engineering students in Chinese universities. Mechanical drawing teaches 
drawing and recognition rules and methods of producing mechanical drafts, which consist of graphics, symbols, words and figures to express design intentions. Mechanical drawing, which requires experience with making and communicating technical documents, is considered a language in engineering circles. ${ }^{[1]}$ The teaching aim of mechanical drawing is to cultivate the students' graphical interpretation ability, plotting ability, inter-space imagination and innovation ability ${ }^{[2]}$.

However, it is often due to a lack of spatial imagination capability and an insufficient opportunity to touch real machine parts that the students cannot imagine the real machine parts. It is also hard to map 3D objects with their 2D projections. As a result, students feel that it is difficult and boring to learn mechanical drawing. It is also a challenge to teachers because they need to explain complicated graphical relationships using ordinary teaching equipment in a limited period of time in the classroom.

Advanced computer and information technologies have promoted the effectiveness of education. AR (Augmented Reality) technology was proposed early in the 1960s, as an important branch of VR (Virtual Reality) that addresses the combination of realworld and computer-generated data ${ }^{[3]}$. It provides supplementary information to reality by superposing virtual objects that are made by computers or other information on to real scenes. Augmented reality systems have been restricted by hardware for a long time, and users have to use a heavy HMD or sit in front of a PC on a desk. In recent years, with the development and promotion of smartphone technology and functions, smartphones are now equipped with some functions, such as calculators, videos, image displays, GPS, mobile networks, touch screens, and pitch detection, and prices continue to drop. Meanwhile, a survey about the mobile phone usage of college students in China shows that mobile phones have become a dominant information media among college students ${ }^{[4]}$. Thus, an augmented reality system based on a smartphone platform offers technologies for university education. Teachers should make the best use of this kind of emerging technology in mechanical drawing courses to promote a more natural study atmosphere, stimulate students' interests and improve learning efficiency.

\section{State of the art}

Kay, Papert and Weiser all believe that pervasive computing offers opportunities for completely changing the mode of teaching and learning. ${ }^{[5][6][7]}$ Considerable effort has exerted to use augmented reality (AR) technology for distributing educational content. The first AR book (Magic book) was developed in 2001 by Billinghurst et al. ${ }^{[8]}$ Kirner et al. presented an interactive book with AR for the teaching and learning of geometric shapes on a PC, and they discussed the use of GeoAR by children in real situations ${ }^{[9]}$. Ángela Di Serio et al. showed that AR technology had a positive impact on the motivation of middle-school students ${ }^{[10]}$. Santoso $\mathrm{M}$ et al. developed digital edutainment content that combines AR technology with tangram toys and proved that users become more engaged and interested when using it than when just using conventional methods ${ }^{[11]}$. It can be seen that $A R$ has great potential in the educational domain. 
Here are some major aspects of educational applications of augmented reality:

- Combining AR technology with a book: Billinghurst et al. developed an AR book, which is an early attempt to explore how we can use a physical object to smoothly transport users between reality and virtual reality ${ }^{[8]}$. Later, the authors added virtual visual and auditory enhancements to an already published story book. Since then, many other AR books have been developed ${ }^{[12]}$.

- Combining AR technology with practical classroom teaching behaviours: Shelton and Hedley use AR technology to teach experiments on the nine planets, ${ }^{[13]}$ which provides evidence that this form of AR has cognitive advantages. Kaufmann and Schmalstieg applied Construct3D using AR technology to teach spatial geometry ${ }^{[14]}$. A great deal of evidence supports the idea that Construct3D is easy to learn, encourages experimentation with geometric constructions and improves spatial skills.

- Combining AR technology with entertainment: Markus Santoso combined a tangram toy and its manual book with AR technology ${ }^{[11]}$. Hye Sun Lee and Jong Weon Lee used augmented reality technology to design an educational game to help students from kindergarten or primary school master knowledge about addition ${ }^{[15]}$.

The works most relevant to our own are presented in [16] and [17]. They all developed instructional systems for drawing courses based on augmented reality. In [16], an augmented book called AR-Dehaes was designed to provide 3D virtual models that help students perform visualization tasks and promote the development of students' spatial ability during a short remedial course. In [17], an instructional system for an engineering drawing course was developed based on augmented reality.

However, these applications have common problems: Because they assist education by matching the content of the virtual environment with the real environment by scanning special marks supported by PC system hardware, they have to design markers while developing the software. The markers need to be published in books, which means the textbooks should be typeset and printed again. To meet the demand of university education, this paper presents a way to apply mobile augmented reality technology more naturally and without special markers to support teaching and learning in mechanical drawing courses.

\section{Theoretical basis}

\subsection{Augmented reality technology}

Augmented reality technology superimposes computer-generated data on top of a user's perception of the real world in real-time. An augmented reality system supplements the real world with virtual computer-generated objects that appear to coexist in the same space as the real world. An augmented reality system has three main characteristics: (1) combining real and virtual objects in a real environment, (2) real-time interactivity, and (3) registering in $3 \mathrm{D}$ or, put another way, aligning real and virtual 
objects. Mobile augmented reality systems provide a similar experience "without constraining the individual's whereabouts to a specially equipped area". ${ }^{[3]}$ Mobile augmented reality technology has three features: augmentation, interaction, and personality.

The primary work process of an augmented reality system is demonstrated in Fig. 1. ${ }^{[18]}$ On the one hand, the real scene video streams captured by camera and other image capture devices are entered into the system and analysed by tracking technology, and registration information is obtained. On the other hand, the virtual information displayed by real-time rendering techniques, with the help of registration information, are combined efficiently with real scenes. In the end, they are protracted together by augmented reality display devices.

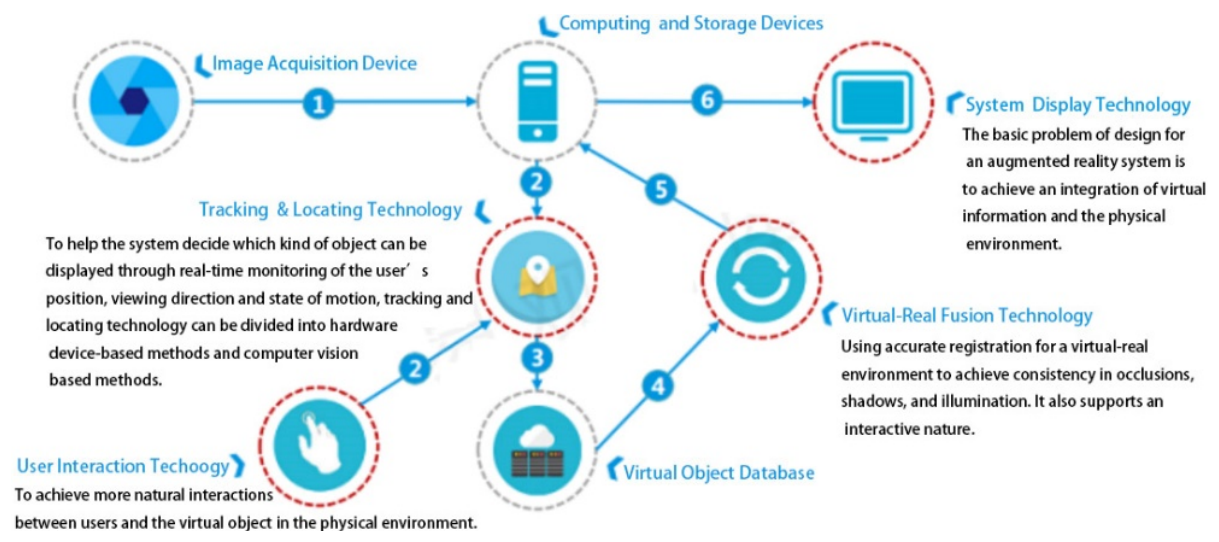

Fig. 1. The primary work process of an augmented reality system

\subsection{Mark-based method and nature-feature-based method}

In a mobile augmented reality system, target recognition methods can be divided into mark-based methods and nature-feature-based methods. The mark-based recognition technology needs us to add special artificial definition marks in advance, and then analyse marks obtained, to recognize graphics in the place and pose of a computational camera. These marks are usually simple graphics with strongly contrasting colours, as shown in Fig. 2. The nature-feature-based recognition technology adopts the natural features of graphics to recognize them directly by analysing the graphics and calculating and testing geometrical features to substitute for marks so that it can recognize the graphics, as shown in Fig. 3. Compared to the mark-based method, the nature-feature-based method has the following advantages. First, no special marks need to be designed; second, the original textbook is used, whereas the mark-based method needs to add marks to the textbook and re-print it; and third, it is easier to use, is more natural for communication and can improve the users' experience. 


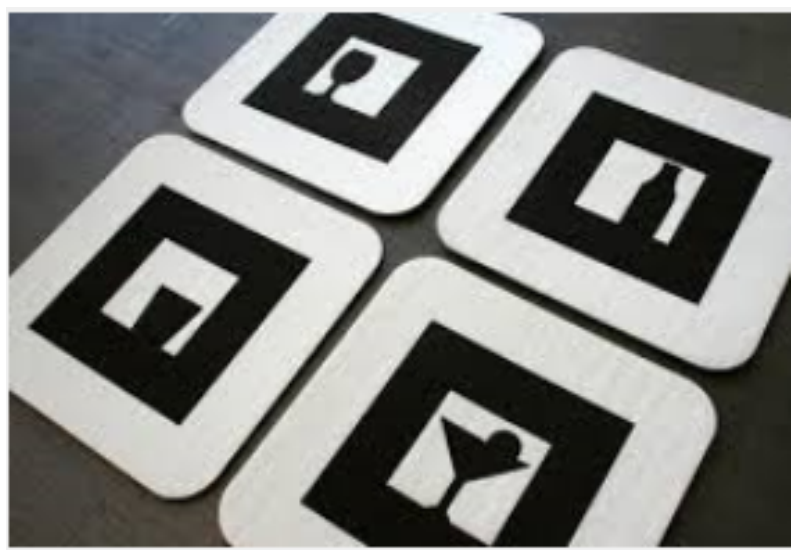

Fig. 2. Markers

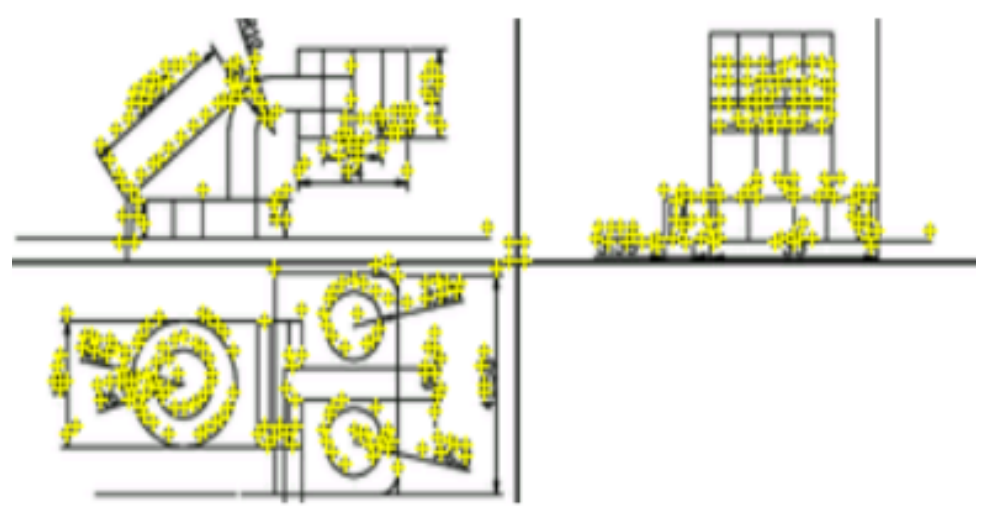

Fig. 3. Nature-feature points in a mechanical 2D drawing

\section{Tracking registration technology}

After recognition, mobile an augmented reality system begins tracking registration with the adoption of the computer vision method. The procedure accomplishes the following steps: (1) track the spatial position and shape of a mobile phone's camera on a target object, (2) calculate the coordinates of the virtual information in the camera according to this information, and 3) match the position-related information with the graphic by projecting their coordinate systems: computing a world coordinate system $\mathrm{W}\left(\mathrm{X}_{\mathrm{W}}, \mathrm{Y}_{\mathrm{W}}, \mathrm{Z}_{\mathrm{W}}\right)$, a camera coordinate system $\mathrm{C}\left(\mathrm{X}_{\mathrm{C}}, \mathrm{Y}_{\mathrm{C}}, \mathrm{Z}_{\mathrm{C}}\right)$, an imaging plane coordinate system $\mathrm{o}(\mathrm{x}, \mathrm{y})$, and a pixel coordinate system $\mathrm{o}_{1}(\mathrm{u}, \mathrm{v})$. The mapping algorithm can be deduced as below:

The transformation between the world coordinate system $\mathrm{W}$ and the camera coordinate system $C$ is shown in Equation 1, where $R_{W C}$ (rotation information) and $T_{W C}$ (displacement information) represent a relative position and shape between $\mathrm{W}$ and $\mathrm{C}$, respectively. 


$$
\mathrm{C}\left(X_{\mathrm{C}}, Y_{\mathrm{C}}, Z_{\mathrm{C}}, 1\right)^{\mathrm{T}}=\mathrm{R}_{\mathrm{WC}} \mathrm{T}_{\mathrm{WC}} \mathrm{W}\left(X_{\mathrm{w}}, Y_{\mathrm{w}}, Z_{\mathrm{w}}, 1\right)^{\mathrm{T}}
$$

The transformation between the camera coordinate system $\mathrm{C}$ and the imaging plane coordinate system o is shown in Equation 2, where $f$ represents the distance between the camera imaging plane and the focus plane.

$$
\mathrm{x}=f X_{c} / Z_{c}, \mathrm{y}=f Y_{c} / \mathrm{Z}_{c}
$$

The transformation between the imaging plane coordinate system o and the pixel coordinate system o1 is shown in Equation 3, where $\lambda$ is the scaling factor between the systems of $\mathrm{o}$ and $\mathrm{W}$ and $\mathrm{K}$ is the camera's internal parameters, as seen in Equation 4.

$$
\begin{aligned}
\lambda \mathrm{o}_{1}(u, v, 1)^{\mathrm{T}} & =\mathrm{KR}_{\mathrm{WC}} \mathrm{T}_{\mathrm{WC}} \mathrm{W}\left(X_{\mathrm{w}}, Y_{\mathrm{w}}, Z_{\mathrm{w}}, 1\right)^{\mathrm{T}} \\
\mathrm{K} & =\left[\begin{array}{ccc}
f / d_{x} & 0 & u_{0} \\
0 & f / d_{y} & v_{0} \\
0 & 0 & 1
\end{array}\right]
\end{aligned}
$$

\section{Development of a mobile AR technology Interactive teaching system for a Course of Mechanical Drawing}

An interactive teaching system for mechanical drawing courses aims to help students understand the relation between three-dimensional mechanical parts and twodimensional projection drawings and solve problems when they study in class or after class. It is also useful in helping teachers to teach efficiently in a limited time during classes. We choose the existing textbook Mechanical Drawing ${ }^{[2]}$ as the resource, and we take advantage of mobile AR technology to develop the interactive teaching system.

\subsection{Requirement analysis}

There are several requirements for an interactive teaching system based on mobile augmented reality technology being used in the teaching and learning of mechanical drawing, as follows:

1. Improve students' familiarity with mechanical parts. The system should be designed to offer a great number of digital models of mechanical parts kept in the database of virtual objects to demonstrate the great variety of mechanical parts models to the utmost degree and improve students' familiarity with mechanical parts.

2. Improve the capability of students' reading of drawings. The system should be designed so that it can virtually overlay three-dimensional mechanical parts models in real two-dimensional projection drawings. This will help students understand the mapping relationship between plane figures and 3-dimension models and improve the capability of students' reading of drawings. 
3. Help students understand sophisticated structures. The system should be designed to offer interactive functions so students can directly control the digital models of mechanical parts in real time, such as zoom in, zoom out and rotation. This will help students understand the sophisticated structures or assembly relationships of mechanical parts.

4. Help students draw the view from a particular perspective. The system should be designed to offer screenshot functions, so students can directly and clearly observe different photos of virtual three-dimensional mechanical parts models from different shooting scales.

5. Help students better understand the content being taught. The teaching system should be designed to offer instructional functions by using embedded animation or video to teach difficult areas of the current mechanical parts models to students.

6. The teaching system should be designed to assist the teacher in class with the aim of surmounting the shortcomings of traditional teaching modes. It could also help students solve problems when they study after class, inspire students' enthusiasm for learning and improve their subjective initiative.

\subsection{Architecture design}

Based on the requirement analysis of the system, a mechanical drawing interactive teaching system needs to gather video images of target objects in realistic environments when paper drawings or textbooks are by the camera on the smart terminal. It determines the location and posture of the camera in the real scene by identifying concrete illustrations in the real scene so it can superimpose the corresponding digitized content on the target object. In this process, the software system needs to undertake a series of related actions to promote the completion of the above tasks. The teaching system is mainly composed of real scene video digital acquisitions, realistic scene target object tracking locations, actual registration, digital content objects and real scene video image overlays, interactive operations, virtual fusion displaying the output and other modules. The architectural design diagram is shown in Fig. 4.

The application design of the teaching system involves the integrated development of a variety of technologies. On the one hand, it involves image recognition, threedimensional tracking registration and other key technologies, which are focused on augmented reality technology, to realize the virtual fusion of the system. On the other hand, the teaching system also involves the digital image technology of the mechanical drawings' digital transformation. In addition, the whole system operates in an intelligent terminal platform, and it also involves high-speed transmission and storage of all kinds of data. Therefore, the main technologies of this teaching system are divided into key technologies, enabling technologies and supporting technologies, and the technical contents of specific levels are shown in Fig. 5 


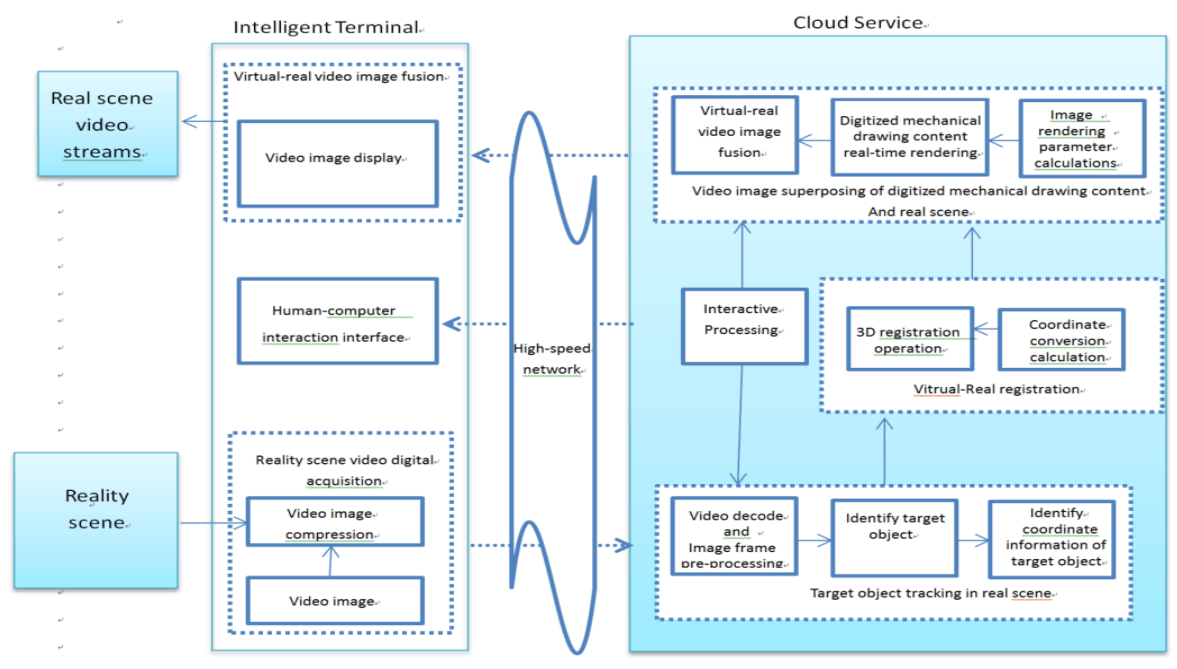

Fig. 4. Architectural design diagram
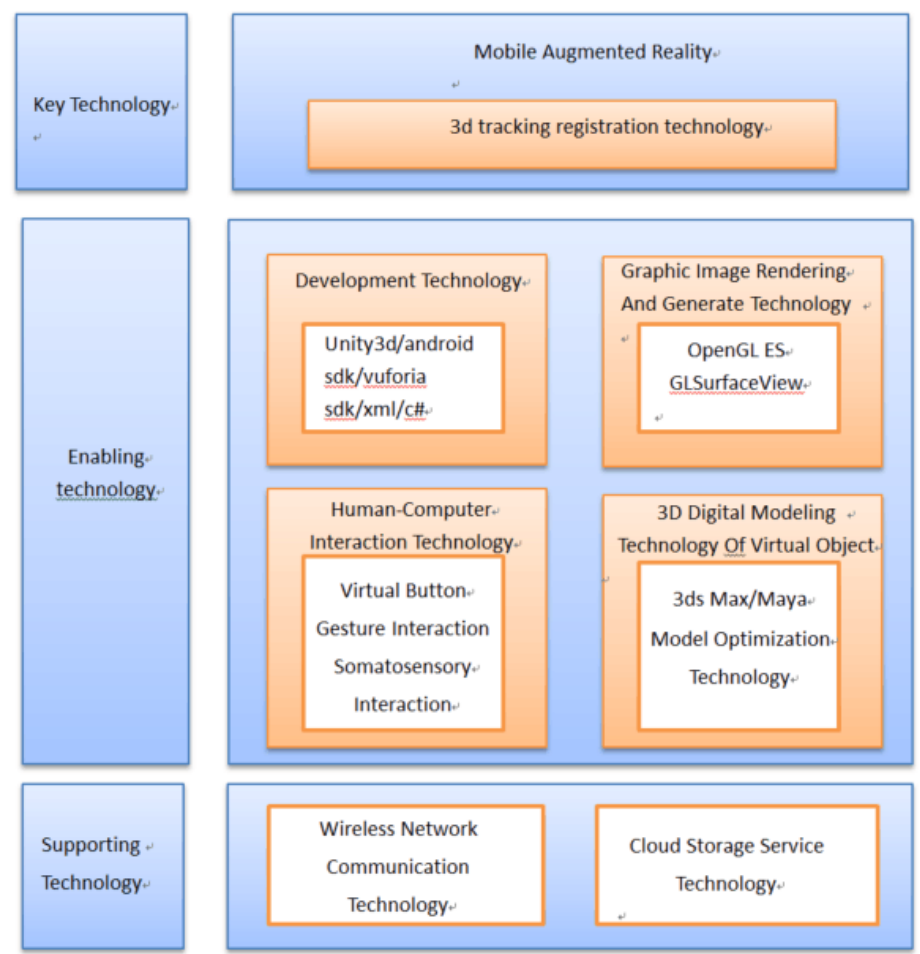

Fig. 5. Primary technology hierarchical structure diagram 


\subsection{Function display}

This teaching system is based on the Unity3D game engine ${ }^{[19]}$, Qualcomm vuforia, and uses $3 \mathrm{ds}$ max for 3D digital models. The functional diagram of the mechanical drawing interactive teaching system is based on the augmented reality approach designed in this paper, as shown in Fig. 6.

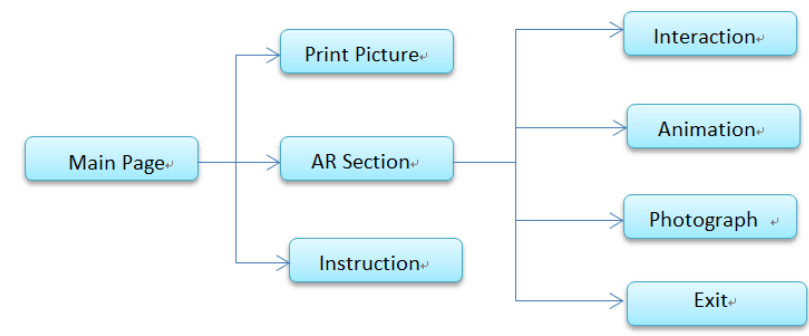

Fig. 6. Functional diagram of Mechanical Drawing interactive teaching system

Starting with the main page shown in Fig. 7, it includes 3 components: the print picture, the instruction page and the augmented reality page.

- Print picture: This page can print or store some classical 2D design drawings

- The instruction page teaches users how to operate this app.

- The main part of this digital instruction system is the augmented reality page. When a user chooses the augmented reality page, the mobile camera will be activated automatically. Next, the user needs to place the mobile camera above the $2 \mathrm{D}$ patterns or a monitor. The characteristic of our system is the absence of a marker, so users directly target $2 \mathrm{D}$ patterns or a monitor. Then, the interactive teaching system will track the picture and visualize the registered digital virtual content of each picture, as is seen in Fig. 8.

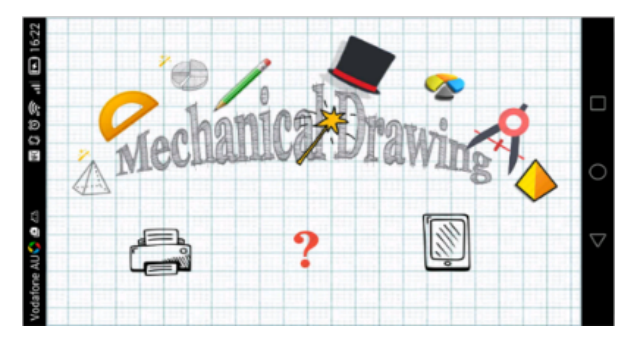

Fig. 7. Main page

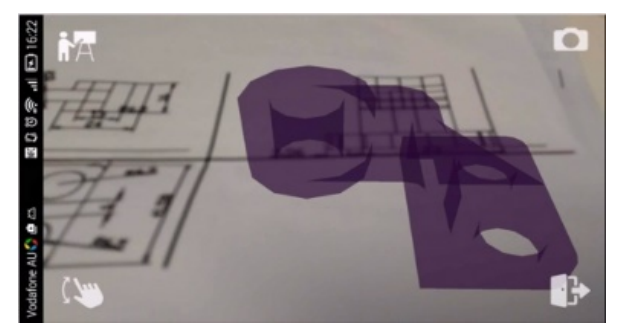

Fig. 8. AR page

In the AR section, there are also 4 function buttons to meet a user's personalized learning requirements, namely, the animation demonstration button in the top left corner in Fig. 5(b), the photograph button in the top right corner in Fig. 5(b), the tangible interaction button in the bottom left corner in Fig. 5(b), and the exit button in the bottom left corner in Fig. 5(b). When the "animation demonstration" button is chosen, a clip of animation will be played to show how the $3 \mathrm{D}$ model is integrated or divided; 
when the "photograph" button is chosen, the current view can be restored. When the "tangible interaction" button is chosen, the user can freely transform, rotate, and scale the 3D model. Tapping on the "exit" button will allow the user to exit the whole system.

When a difficulty is faced in the teaching and learning of mechanical graphics using a textbook, one can use the applications by aim it the graphics, and then, the corresponding digital content will overlap the graphics. We selected 3 typical cases as examples, which involve the basic mechanical drawing skills required of students.

Fig. 9 is a position example, helping students understand points in space on a curved surface. Fig. 10 and 11 are decomposed graphics to help students understand assemblies, such as the differences between intersections and tangents. Fig. 12 helps students understand complex graphics.

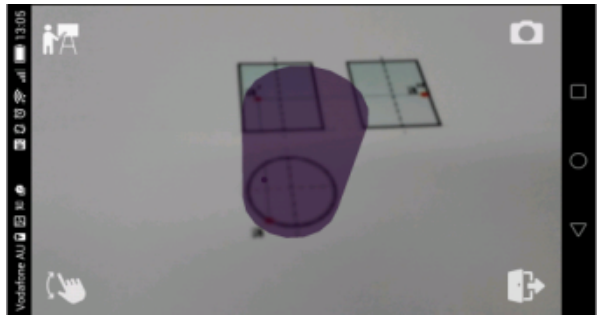

Fig. 9.

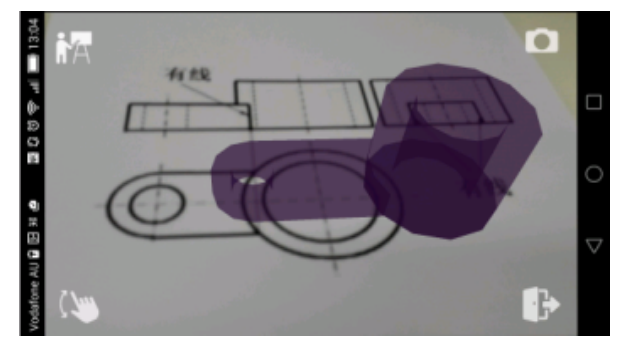

Fig. 11.

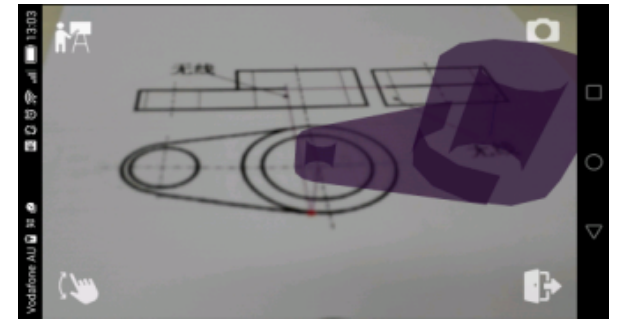

Fig. 10.

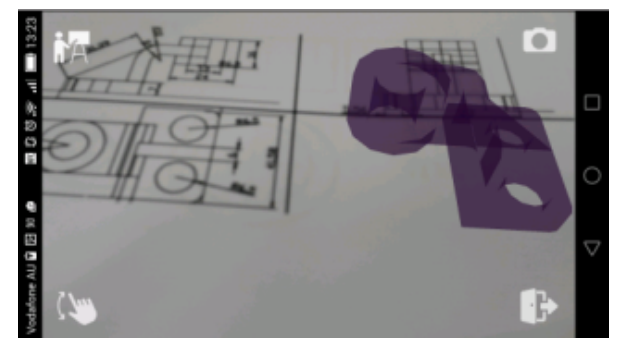

Fig. 12.

\subsection{Effect check}

To evaluate the effect of the teaching method designed in this paper, a case study of a mechanical drawing course was carried out. Two 35-student classes (Class 1 and Class 2) of undergraduate students were surveyed.

For Class 1, based on the ordinary teaching method, an interactive teaching system using mobile AR technology was adopted so that students could understand the content being taught more easily in class. This approach could also help students solve problems when they study after class. However, for Class 2, only the ordinary teaching method was adopted, which mainly includes an electronic teaching plan, teaching wall chart, a presentation of real materials and interpretation and drafting practice after class. After 18 weeks (72 class hours), a questionnaire survey was completed by 
the students of the two classes to analyses and evaluate the teaching effects. Table 1 shows the evaluation results of the questionnaire survey.

Under the same circumstances, class 1 , for which the mobile augmented reality interactive teaching system was adopted, is significantly superior to class 2 , for which only the ordinary teaching method was adopted, with regard to the students' degree of proficiency in the key, difficult content areas of the course, their spatial imagination capability, and their interest in learning and study after class.

Table 1. Survey of effect of the virtual reality teaching technology on course learning

\begin{tabular}{|l|c|c|c|c|}
\hline Class & $\begin{array}{c}\text { Help mastering } \\
\text { key, difficult } \\
\text { content areas of } \\
\text { the class }\end{array}$ & $\begin{array}{c}\text { Help comprehen- } \\
\text { sion and estab- } \\
\text { lishment of inter- } \\
\text { space imagination }\end{array}$ & $\begin{array}{c}\text { Help stimulate } \\
\text { students' study } \\
\text { interest }\end{array}$ & $\begin{array}{c}\text { Help students' } \\
\text { learning and study } \\
\text { after class }\end{array}$ \\
\hline Experimental Class 1 & $77.1 \%$ & $85.7 \%$ & $88.6 \%$ & $82.8 \%$ \\
\hline Control Class 2 & $45.7 \%$ & $51.4 \%$ & $42.8 \%$ & $37.1 \%$ \\
\hline
\end{tabular}

The students' exam scores each month also indicate that there were differences between class 1 and class 2 during the semester. For the purpose of evaluation, the average scores were calculated. As Table 2 shows, the two classes appeared to be equal in the first month's exam, but the scores of the experimental Class 1 became superior to those of the control class 2 starting in the second month. This is mainly because that the students needed time to adapt to the new teaching method. When the students from the experimental group became used to the new interactive teaching system in the first month, then they were able to surpass the control group. This indicates that the new teaching method can help students improve their academic record.

Table 2. Evaluation on students' course knowledge and skills $($ Score $=100)$

\begin{tabular}{|l|c|c|c|c|}
\hline & 1st month & 2nd month & 3rd month & Final exam \\
\hline Experimental Class 1 & 78.65 & 81.31 & 83.11 & 84.23 \\
\hline Control Class 2 & 79.53 & 80.25 & 80.01 & 81.03 \\
\hline
\end{tabular}

\section{Conclusions}

In this paper, a new type of interactive teaching system based on mobile AR technology is designed and implemented. The teaching system has been applied to the experimental teaching and learning of mechanical drawing. The questionnaire survey of the students at the end of a semester and the evaluation of students' performance show that the students are satisfied with the new of type interactive teaching system designed in this paper because it is helpful in arousing students' learning interest, enhancing their inter-space imagination capability and improving their academic record. The new mobile AR teaching system can not only transcend the limitation of time and space in the classroom for students but also help teachers focus on teaching instead of on preparing teaching aids. This intuitive visual experience, which allows 
for quick and convenient operations by users, can solve the abstract problems of mechanical drawing courses.

The limitations of the study are as follows. Currently, mobile AR technology is in the developmental phase, and relatively few enterprises have mature technology in product development. Great developmental difficulties and higher costs are the main bottlenecks to the popularity of mobile AR teaching system for mechanical drawing courses. The stage of evaluating the teaching effect of this approach was limited by time, manpower, material resources and money, so the study had a shorter demonstration application period and smaller sample size, which led to the lack of a comprehensive detailed data analysis. Therefore, the next stage will be for our team to take further steps to study this by building a relatively stable AR teaching system development group, exploring industrialized models, demonstrations and applications, and improving the teaching effect evaluation mechanism.

To sum up, the practice of utilizing advanced digital information technologies for teaching and learning has been gradually accepted and adopted by the public in the new digital age; information technology is developing rapidly and various emerging teaching systems are increasingly attracting attention and have been adopted by educators of different subjects. Based on the attempt to apply an interactive teaching system based on mobile AR technology in the teaching and learning of mechanical drawing, we realize that mobile augmented reality technology can largely promote the effectiveness of education and provides a new idea and direction for educational reform.

\section{Acknowledgment}

Project Supported by CSC Scholarship ; applied basic research plan of Wuhan Science and Technology Bureau with grant No.2017010201010105; Shenzhen Science and Technology Innovation Committee with grant No. JCYJ20170306170559215; Jiangxi Educational Committee with grant No. GJJ151282 and the Jingdezhen Committee of Science and Technology with Grant No.2013010.

\section{$7 \quad$ References}

[1] Sun tingli, (2016) Mechanical Drawing Textbook, the University Press, Jiangxi, China

[2] Wang shuxia, Zhang qian, (2017)Diversity practice teaching reform of Mechanical Drawing, Journal of Engineering Graphics, 38(3):453-457.

[3] Azuma R T. (1997) A survey of augmented reality[J]. Presence: Teleoperators and virtual environments, 6(4): 355-385. https://doi.org/10.1162/pres.1997.6.4.355

[4] The use of mobile phones survey of university students ,2016, http://www.wm23.cn/art/525467.html

[5] Kay A., (2003) The Dynabook revisited, A conversation with Alan Kay, The Book \& The Computer Online Symposium,

[6] Papert, S., (1993) The children's machine: Rethinking school in the age of the computer, New York, NY: Basic Books 
Paper-Construction of Interactive Teaching System for Course of Mechanical Drawing Based on Mob...

[7] Weiser M., (1991) The computer for the 21st century, Scientific American, 265(3): 94104https://doi.org/10.1038/scientificamerican0991-94

[8] Billinghurst M, Kato H, Poupyrev I., (2001)The magicbook-moving seamlessly between reality and virtually, Computer Graphics \& Applications, 21(3): 6-8

[9] Kirner T G, Reis F M V, Kirner C., (2012)Development of an interactive book with Augmented Reality for teaching and learning geometric shapes, Information Systems and Technologies (CISTI), 2012 7th Iberian Conference on IEEE, 1-6.

[10] Di Serio A, Ibáñez M B, Kloos C D. (2013), Impact of an augmented reality system on students' motivation for a visual art course, Computers \& Education, 586-596. https://doi.org/10.1016/j.compedu.2012.03.002

[11] Santoso M, Yan W F, Gook L B., (2012) Development of edutainment content for elementary school using mobile augmented reality, 4th International Conference on Computer Research and Development, IPCSIT, 39: 14-21

[12] Grasset R, Dünser A, Billinghurst M., (2008) Edutainment with a mixed reality book: a visually augmented illustrative childrens' book, Proceedings of the 2008 International Conference on Advances in Computer Entertainment Technology. ACM, 292-295. https://doi.org/10.1145/1501750.1501819

[13] Shelton B E, Hedley N R., (2004)Exploring a cognitive basis for learning spatial relationships with augmented reality, Technology, Instruction, Cognition and Learning, 1(4): 323

[14] Kaufmann H, Schmalstieg D., (2003) Mathematics and geometry education with collaborative augmented reality, Computers \& Graphics, 27(3): 339-345https://doi.org/10.1016/ S0097-8493(03)00028-1

[15] Lee H S, Lee J W. (2008), Mathematical education game based on augmented reality, Technologies for E-Learning and Digital Entertainment, Springer Berlin Heidelberg, 442450

[16] Martín-Gutiérrez J, Saorín J L, Contero M, et al., (2010) Design and validation of an augmented book for spatial abilities development in engineering students, Computers \& Graphics, 34(1): 77-91. https://doi.org/10.1016/j.cag.2009.11.003

[17] Chen H, Feng K, Mo C, et al. (2011), Application of Augmented Reality in Engineering Graphics Education, IT in Medicine and Education (ITME), International Symposium on IEEE, 2: 362-365.

[18] YIGUAN think tank: augmented reality Research report of China market ,2015, http://www.useit.com.cn/thread-9923-1-1.html

[19] Unity3D: https://unity3d.com/cn/

\section{Authors}

Cheng Juan is a associate professor in Jingdenzhen University and a PHD student in International School of Software, Wuhan University, China. Her research interests include digital media, 3-dimensional art, Augmented reality and virtual reality (ilovesweet@gmail.com, ORCID: 0000-0002-2886-5538).

Wang Yulin is a full professor and $\mathrm{PhD}$ supervisor in International School of Software, Wuhan University, China. His research interests include digital rights management, digital watermarking, multimedia and network security, and signal processing.

Tjondronegoro Dian W. focuses on research, teaching, and industry engagement in mobile and multimedia computing. He has lead the mobile research and develop- 
ment for three Cooperative Research Centers (CRCs): CRC Smart Services (smart video optimization for mobile and multi-channel delivery), CRC Rail Innovation (mobile technologies for delivering real-time transit information and mobile payment), and CRC Young and Well (mobile music tool for mood journey).

Wei Song is Professor at Shanghai ocean university, China. Her research interests include data analysis, algorithm development and user experience.

Article submitted 17 October 2017. Resubmitted 12 December 2017. Final acceptance 04 February 2018. Final version published as submitted by the authors. 